\title{
MORFOGÊNESE DA PALMA FORRAGEIRA IRRIGADA POR GOTEJAMENTO ${ }^{1}$
}

\author{
POLIANA DE CALDAS PEREIRA ${ }^{2 *}$, THIERES GEORGE FREIRE DA SILVA ${ }^{3}$, SÉRGIO ZOLNIER $^{2}$, JOSÉ EDSON $^{3}$ \\ FLORENTINO DE MORAIS ${ }^{3}$, DJALMA CORDEIRO DOS SANTOS ${ }^{4}$
}

\begin{abstract}
RESUMO - Objetivou-se avaliar a evolução do crescimento de clones de palma forrageira submetidos a diferentes condições de disponibilidade de água no Semiárido brasileiro durante um ano de anomalia climática (biênio 2012-2013). O experimento foi conduzido no primeiro ano produtivo do segundo ciclo da cultura (março de 2012 a fevereiro de 2013) no município de Serra Talhada (PE). O delineamento experimental foi em esquema fatorial $3 \times 3$ com três repetições, sendo utilizados três intervalos de aplicação de uma lâmina fixa de 7,5 mm (7, 14 e 28 dias) e três clones de palma forrageira (IPA: IPA Sertânia; MIU: Miúda; e OEM: Orelha de Elefante Mexicana). Durante o experimento foram realizadas avaliações biométricas para análise morfológica da planta e dos cladódios ao longo do tempo. Constatou-se que as condições de disponibilidade de água não apresentaram influências significativas $(\mathrm{P}>0,05)$ sobre a maioria dos valores absolutos e relativos das variáveis de crescimento dos três clones. Já quando se compararam os diferentes clones, independentemente da condição de disponibilidade de água, observou-se que em termos de valores absolutos a OEM apresentou as maiores médias, diferindo apenas da MIU. Quanto a avaliação ao longo do tempo houve aumento das taxas de crescimento nos últimos meses do ciclo decorrente da ocorrência de eventos de precipitação pluviométrica, que em conjunto com a aplicação dos tratamentos de irrigação promoveram melhores incrementos biométricos nos clones OEM e IPA Sertânia.
\end{abstract}

Palavras-chave: Anomalia climática. Irrigação. Nopalea spp. Opuntia spp. Semiárido.

\section{GROWTH EVOLUTION OF CACTUS FORAGE DRIP IRRIGATED}

\begin{abstract}
The objective was to evaluate the growth of clones of forage cactus, subjected to different conditions of water availability in the Brazilian Semiarid, during a year of climate anomaly (biennium 2012-2013). The experiment was carried out in the first production year of the second crop cycle (March 2012 to February 2013), in the district of Serra Talhada, State of Pernambuco. The experiment was carried out in a randomized block design using a factorial arrangement $3 \times 3$ with three replications, being used three intervals of application of a fixed irrigation depth $(7.5 \mathrm{~mm}),(7,14$ and 28 days), and three forage cactus clones (IPA: IPA Sertânia; MIU: Míuda and, OEM: Orelha de Elefante Mexicana). Eight biometric campaigns were performed during the experiment period for morphological analysis of the plants and cladodes along the time. It was found that water availability conditions showed no significant influence $(\mathrm{P}>0.05)$ on the majority of the absolute and relative values of the growth variables of the three forage cactus clones. However, when comparisons were performed among different clones, regardless of the water availability conditions, it was observed that, in terms of absolute values, the OEM had the highest means, differing only from the MIU clone. Regarding evaluations over time, there were increased growth rates in the last months of the crop cycle because of the occurrence of rainfall, which in conjunction with the application of the irrigation treatments promoted the best biometric increments for the OEM and IPA Sertânia clones.
\end{abstract}

Keywords: Climate anomaly. Irrigation. Nopalea spp. Opuntia spp. Semiarid.

\footnotetext{
*Autor para correspondência

${ }^{1}$ Recebido para publicação em 12/04/2014; aceito em 30/04/2015.

Resultado da Dissertação de Mestrado e de Projeto de Pesquisa financiado pela FACEPE/CNPq/IPA/UFRPE.

${ }^{2}$ Universidade Federal de Viçosa - UFV/DEA, CEP 36570-000, Viçosa (MG); po.caldas@hotmail.com, zolnier@ufv.br.

${ }^{3}$ Unidade Acadêmica de Serra Talhada - UAST/UFRPE, Caixa Postal 063, CEP 56900-000, Serra Talhada (PE); thieres_freire@yahoo.com.br, joseedosn50@hotmail.com.

${ }^{4}$ Instituto Agronômico de Pernambuco, BR 232, km 253, CEP 56500-000, Arcoverde (PE); djalma.cordeiro@ipa.br.
}

Revista Caatinga, Mossoró, v. 28, n. 3, p. 184 - 195, jul. - set., 2015 


\section{INTRODUÇÃO}

A pecuária na região Semiárida do Brasil sofre influências da variabilidade temporal e espacial das chuvas, o que gera a busca por plantas forrageiras que sejam adaptadas às condições climáticas locais (RAMOS et al., 2011). Entre essas plantas a mais utilizada na alimentação animal no Nordeste brasileiro é a palma forrageira (Opuntia spp. e Nopalea spp.) (BISPO et al., 2007; SILVA et al., 2010), a qual é uma espécie xerófila que devido as suas características morfofisiológicas possibilita a sobrevivência em ambiente com escassez de água, alta temperatura e solos de baixa fertilidade (HERNÁNDEZ et al., 2004; TEGEGNE et al., 2007).

Apesar desta adaptabilidade, seu crescimento e desenvolvimento variam com as oscilações das condições meteorológicas. Souza et al. (2008) relatam que o potencial produtivo dessa cultura se expressa de forma mais significativa em regiões com precipitações anuais entre $368 \mathrm{~mm}$ e $812 \mathrm{~mm}$ e temperaturas médias variando de $16,1^{\circ} \mathrm{C}$ a $25,4^{\circ} \mathrm{C}$.

Em regiões produtoras de palma, quando a precipitação pluviométrica local não atinge os níveis considerados ideais, faz-se necessário o uso de irrigação para atender a necessidade hídrica da referida cultura (MERWER et al., 1997).

Estudos que avaliam a resposta daquela espécie ao déficit hídrico são poucos e os existentes consideram apenas o retorno produtivo (HERNÀNDEZ et al., 2004; OLIVEIRA et al., 2011; SANTOS et al., 2012). Uma alternativa é a mensuração de variáveis de crescimento, que demonstram as alterações da morfologia das espécies a distintas condições de disponibilidade hídrica no ambiente (SILVA; NEVES, 2011). Essa técnica denomina-se morfogênese, a qual permite exibir os distintos padrões de resposta das plantas, contribuindo para a tomada de decisão no manejo de diferentes espécies (CUNHA et al., 2012).

Por sua vez, o Nordeste brasileiro sofre forte influência de fenômenos oceânico-climáticos, como Dipolo do Atlântico e El Niño Oscilação Sul, resultantes da interação oceano e atmosfera, sendo considerados como as principais causas da variabilidade climática em várias regiões do Planeta, sobretudo na América do Sul (BERLATO et al., 2005). Em anos de anomalia, os níveis pluviométricos tendem a ser abaixo das normais climatológicas e a demanda atmosférica aumenta demasiadamente, como resultado do incremento térmico e redução da umidade do ar. O último registro de um fenômeno oceânicoclimático (Dipolo do Atlântico), que resultou em anomalias das variáveis meteorológicas, ocorreu no biênio 2012-2013. Estudos têm destacado o efeito dessas anomalias sobre a produtividade de culturas agrícolas (BERLATO et al., 2005; MINUZZI et al., 2007), porém não o registro do efeito desses fenômenos sobre o sistema de produção da palma forrageira.

Embora a palma seja muito estudada em ter- mos de influência do manejo, a exemplo da adubação, espaçamento de plantio, bem como diferenças entre clones (RAMOS et al., 2011; SILVA et al., 2010), não existem estudos que abordam a sua morfogênese sob diferentes níveis de disponibilidade hídrica, durante a ocorrência de fenômenos oceânico -climáticos. A identificação do comportamento dos seus parâmetros morfológicos é uma ação importante para a elaboração de critérios para a seleção de clones dessa espécie e a identificação das características que mais influenciam na sua produção.

Nesse contexto, objetivou-se avaliar a evolução do crescimento de clones de palma forrageira submetidos a diferentes condições de disponibilidade de água na região do Semiárido brasileiro, durante um ano de anomalia climática (biênio 2012-2013).

\section{MATERIAL E MÉTODOS}

O estudo foi feito na Estação Experimental do Instituto Agronômico de Pernambuco-IPA, na Latitude $7^{\circ} 57^{\prime} \mathrm{S}$, longitude $38^{\circ} 11^{\prime} \mathrm{O}$ e altitude $506 \mathrm{~m}$, no município de Serra Talhada, Pernambuco, localizado na região Semiárida do Nordeste brasileiro. A área está situada em uma região com clima predominante do tipo BSwh', conforme a "Classificação Climática de Köppen”, que o enquadra como tropical seco, tendo como características marcantes os baixos valores de precipitação pluviométrica (média de 350 a $700 \mathrm{~mm} / \mathrm{ano}$ ) e elevadas temperaturas do ar, de forma que a demanda atmosférica excede a precipitação (ANDRADE et al., 2010). Especificamente para essa localidade, a média histórica da precipitação pluviométrica fica em torno de $642 \mathrm{~mm}^{a_{n}{ }^{-1}}$, com médias de temperatura do ar variando entre 20,1 a $32,9^{\circ} \mathrm{C}$ e umidade relativa do ar em torno de $63 \%$.

$\mathrm{O}$ período experimental compreendeu o primeiro ano (março de 2012 a fevereiro de 2013) do segundo ciclo da palma forrageira, o qual tem duração de dois anos (colheita bienal). Ao longo do tempo foram monitoradas as variáveis meteorológicas (temperatura, ${ }^{\circ} \mathrm{C}$; umidade relativa do ar, \%; precipitação pluviométrica, mm; radiação solar global, MJ $\mathrm{m}^{-2} \operatorname{dia}^{-1}$ ) por meio de uma estação automática pertencente a Agência Pernambucana de Águas e Clima - APAC/ITEP, localizada a cerca de $700 \mathrm{~m}$ da área de cultivo.

O experimento foi conduzido em uma área de aproximadamente $864 \mathrm{~m}^{2}(15 \times 57,6 \mathrm{~m})$, cujo solo é classificado como Argissolo Vermelho-Amarelo eutrófico de textura franco arenoso. O plantio foi realizado em fevereiro de 2010 utilizando três clones de palma forrageira, a Orelha de Elefante Mexicana/ IPA-200016 (Opuntia stricta (Haw.) Haw.), a Miúda/IPA-100004 e a IPA-Sertânia/IPA-200205, ambos Nopalea cochenillifera Salm Dyck. Os clones foram plantados com espaçamento de $0,2 \mathrm{~m}$ entre os cladódios e de $1,6 \mathrm{~m}$ entre linhas, tendo $50 \%$ do comprimento do cladódio enterrado no solo. Durante os 
dois primeiros anos o cultivo foi conduzido sob condições de sequeiro.

Em março de 2012 houve a primeira colheita bienal da área, preservando-se o cladódio basal (cladódio utilizado no plantio). O segundo ciclo produtivo da cultura foi conduzido sob irrigação, utilizando um sistema de gotejamento, com uniformização de distribuição de água de $97 \%$, e os gotejadores espaçados por $0,4 \mathrm{~m}$, com vazão de $1,35 \mathrm{~L} \mathrm{~h}^{-1}$.

Antes da imposição dos tratamentos com as distintas frequências de irrigação o solo foi colocado em capacidade de campo com a aplicação de lâminas de uniformização, de junho até julho de 2012, após o período de chuvas na região. E se estendeu de agosto de 2012 até fevereiro de 2013, com a aplicação dos tratamentos de irrigação, resultando em três meses do ano em condições de sequeiro (março, abril e maio de 2012) e nove em condições irrigadas, dos quais sete meses com a aplicação dos tratamentos. Para os eventos de irrigação foi usada água do "Açude Saco", nas proximidades da área experimental, em que a condutividade elétrica variou entre 1,1 a $1,6 \mathrm{dS} \mathrm{m}^{-1}$ ao longo da cultura.

O experimento foi composto por um delineamento em blocos ao acaso, com três repetições, em arranjo fatorial $(3 \times 3)$, no qual as parcelas foram constituídas por três frequências de irrigação $(F)(7$, 14 e 28 dias), resultantes da aplicação de uma lâmina fixa $(7,5 \mathrm{~mm})$, e as subparcelas formadas pelos três clones de palma forrageira (IPA: IPA Sertânia, MIU: Miúda e OEM: Orelha de Elefante Mexicana), totalizando 27 subparcelas. Cada subparcela tinha $32 \mathrm{~m}^{2}$ ( 5 x 6,4m) de área total, sendo $12,8 \mathrm{~m}^{2}(4 \times 3,2 \mathrm{~m}) \mathrm{de}$ área útil, totalizando nove tratamentos experimentais, quais sejam: IPA-F7; IPA-F14; IPA-F28; MIU-F7; MIU-F14; MIU-F28; OEM-F7; OEM-F14 e OEMF28.

A lâmina de 7,5 mm foi adotada com base em informações levantadas em áreas de produtores de palma forrageira do Estado do Rio Grande do Norte, que realizavam a irrigação da cultura com lâminas de $5,0 \mathrm{~mm}$ a cada 14 dias. Esses valores foram utilizados como referência para estabelecer diferentes condições de disponibilidade de água, utilizando-se uma lâmina de irrigação fixa acima $(7,5 \mathrm{~mm})$ do valor de $5,0 \mathrm{~mm}$, antes citado, e três frequências de irrigação (7; 14; e 28 dias) para os três clones (IPA, MIU e OEM).

Ao longo do período experimental foram realizadas eventuais capinas para eliminação de plantas invasoras, aplicação de produtos químicos (controle de lagartas com Losban a $0,15 \%$ e de cochonilhas de escama com óleo mineral a $2 \%$ ) e adubação, seguindo as recomendações do Instituto Agronômico de Pernambuco-IPA, aplicando-se, mensalmente, $50 \mathrm{~kg}$ $\mathrm{ha}^{-1}$ de NPK (14-0-18).

Durante o período experimental (março de 2012 a fevereiro de 2013) mensalmente foram realizadas avaliações biométricas, sendo a primeira em julho de 2012, aos 150 dias após o corte (DAC), até o término do experimento, em fevereiro de 2013 (359 DAC), totalizando oito campanhas durante todo esse período.

As avaliações biométricas consistiram da mensuração das características morfológicas da planta e do cladódio, conforme metodologia mencionada por Silva et al. (2010). Para isso, foram utilizadas três plantas por repetição, totalizando nove por tratamento, com o registro da altura (AP), largura (LP), o número total de cladódios por planta $(\mathrm{NCP})$, número de total de cladódios de primeira ordem (NC1), de segunda ordem (NC2), até " $n$ " ordens, conforme o surgimento de cada unidade em relação ao cladódio basal.

Antes da realização das medidas biométricas foi escolhida uma ramificação na planta, e a partir dela registrada a largura (LC), comprimento (CC), perímetro (PC) e espessura (EC) dos cladódios, conforme a ordem de surgimento dos mesmos na referida ramificação. Finalmente, a área dos cladódios (AC), por ordem de inserção na planta, foi estimada de acordo com as equações propostas por Miranda et al. (2011), que calibraram modelos lineares $(\mathrm{AC}=\mathrm{a}$ $\mathrm{x}+\mathrm{b}$ ) para os mesmos clones avaliados no presente trabalho. Esses autores encontraram os respectivos valores para os coeficientes "a" e "b" de 0,6972 e 19,3890 no clone IPA Sertânia, 0,7327 e 3,3339 no clone Miúda e de 0,7927 e -29,1373 no clone Orelha de Elefante Mexicana, sendo que " $x$ " corresponde a variável independente, obtida pelo produto entre o comprimento e a largura dos cladódios (CC x LC).

Primeiramente, foram determinados os valores médios absolutos da última avaliação biométrica e os valores médios relativos das taxas de crescimento, obtidos pela diferença entre os dados biométricos da primeira e da última medição. Em ambos pretendeu-se analisar a influência das diferentes condições de disponibilidade hídrica sobre o crescimento dos clones. Além disso, foram estimadas as taxas de crescimento de cada parâmetro biométrico ao longo do tempo, por meio do ajuste dos valores observados aos modelos estatísticos disponíveis no software Sigmaplot (SIGMAPLOT, 2004). Nesse caso, foi utilizado dias após o corte (DAC) como variável independente, visando avaliar a evolução do crescimento da cultura. Foram ajustados modelos exponenciais com 2 e 3 parâmetros e em seguida derivados, utilizando-se o software Maple (MAPLESOFT, 2014), onde seus resultados proporcionaram a determinação das taxas de crescimento de cada variável biométrica (SILVA et al., 2014).

Os dados biométricos foram comparados entre os clones de palma forrageira e ao longo do tempo para todas as variáveis de crescimento a partir da análise de variância (ANOVA). As médias significativas foram analisadas pelo teste de Tukey, ao nível de $5 \%$ de probabilidade, utilizando o software GENES (Genética Quantitativa e Estatística Experimental) (CRUZ, 2013). 


\section{RESULTADOS E DISCUSSÃO}

Ao longo do período de março de 2012 a fevereiro de 2013 houve a ocorrência do fenômeno atmosférico conhecido como Dipolo do Atlântico, o qual resultou baixos valores de precipitação pluvio- métrica e de umidade relativa do ar, e estiveram associados a temperaturas do ar mais elevadas em relação a normal climatológica. A precipitação acumulada nos doze meses de ciclo foi de $211 \mathrm{~mm}$, representando apenas $33 \%$ da média histórica (642 mm), conforme destacada na Figura 1.
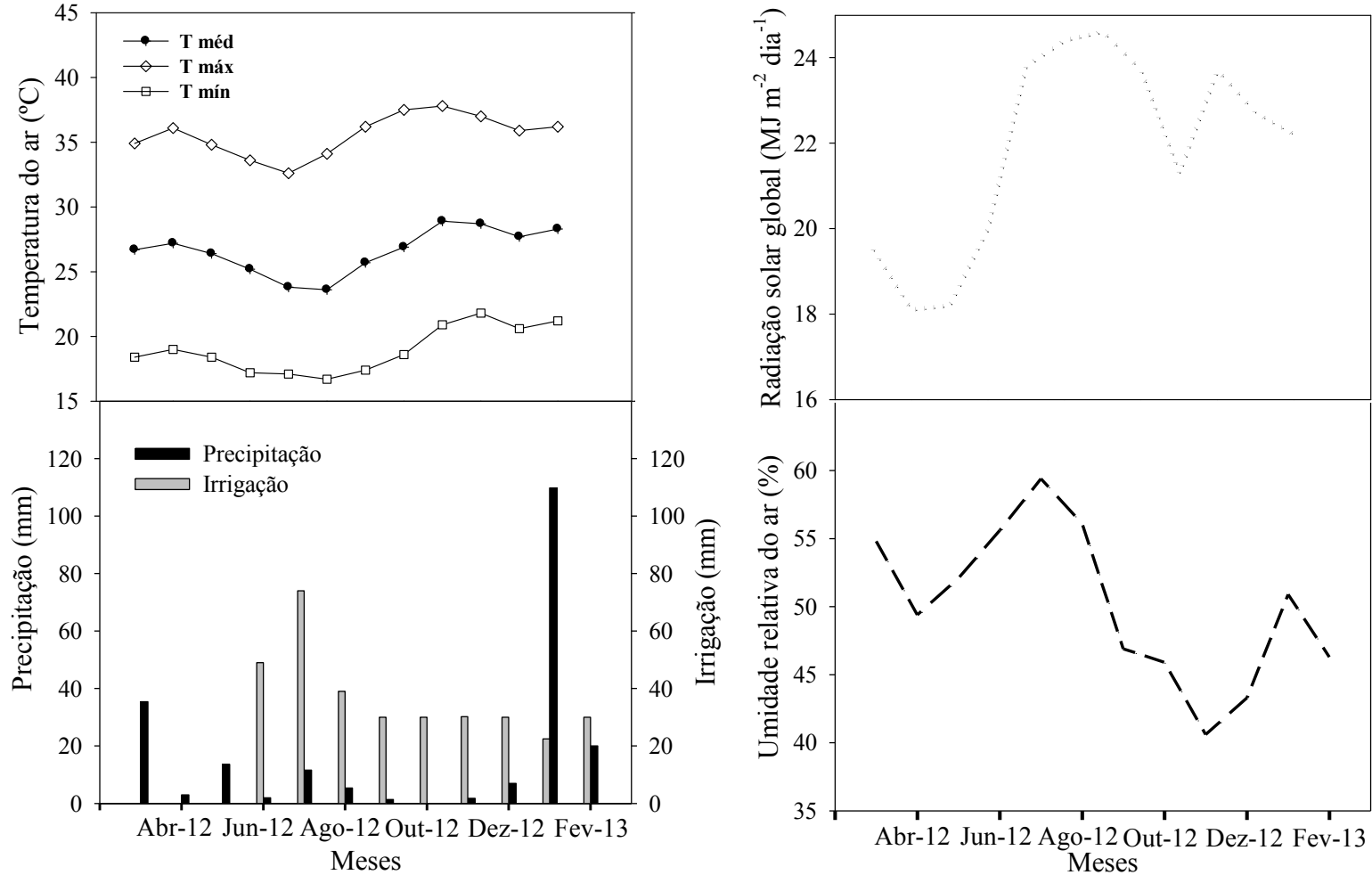

Figura 1. Variáveis meteorológicas ao longo do período experimental (março de 2012 a fevereiro de 2013) em áreas cultivadas com clones de palma forrageira, no munícipio de Serra Talhada (PE).

Cada clone recebeu 188,105 e $68 \mathrm{~mm}$, conforme a frequência de irrigação de 7,14 e 28 dias. Todavia, quando somadas à lâmina de uniformização $(159 \mathrm{~mm})$ mais a precipitação pluviométrica durante o período de março de 2012 a fevereiro de 2013, o total de água recebido pela cultura em cada condição de disponibilidade hídrica foi de 558, 475, $438 \mathrm{~mm}$, respectivamente.

Durante o período experimental foram constatados altos valores de temperaturas médias mensais entre 23,6 a $28,9^{\circ} \mathrm{C}$, com valores de temperaturas máxima e mínima, que variaram de 32,6 a 37,8 e 16,7 a $21,6^{\circ} \mathrm{C}$, respectivamente. Em decorrência do baixo nível de precipitação e altas faixas de temperatura, a umidade relativa do ar apresentou uma varia- ção mensal entre 40,6 a 59,4\%, com uma média durante o período de análise de $50 \%$. Todos esses valores são acima do limite crítico para a cultura, conforme citado por Souza et al. (2008), o que pode promover modificações no crescimento da cultura.

Pela análise dos valores absolutos do crescimento dos clones, obtidos na última campanha biométrica (fevereiro de 2013), verificou-se que as distintas condições de disponibilidade hídrica não proporcionaram efeitos $(\mathrm{P}>0,05)$ para a maioria das variáveis analisadas (Tabela 1). Este fato está associado a reduzida lâmina de água aplicada ao longo do tempo, nas três condições de disponibilidade hídrica. Os valores médios das variáveis biométricas que não apresentaram efeitos são apresentados na Tabela 1. 
Tabela 1. Valores médios absolutos das variáveis de crescimento de clones de palma forrageira (IPA: IPA Sertânia; MIU: Miúda, OEM: Orelha de Elefante Mexicana) obtidos no mês de fevereiro de 2013, em condições irrigadas no município de Serra Talhada (PE)

\begin{tabular}{lcccccccccc}
\hline Clone & AP & LP & NCP & NC1 & CC1 & CC2 & ECB & EC1 & PC2 & AC2 \\
\hline IPA & 52,1 & 49,8 & 9,89 & 6,37 & 22,4 & 18,8 & 34,2 & 18,5 & 44,1 & 149 \\
MIU & 47,5 & 48,8 & 13,9 & 5,52 & 16,5 & 16,3 & 29,4 & 14,1 & 39,0 & 127 \\
OEM & 46,9 & 56,8 & 13,5 & 8,11 & 23,8 & 10,4 & 25,5 & 11,8 & 27,3 & 74,6 \\
Médias & 48,8 & 51,8 & 12,4 & 6,67 & 20,9 & 15,2 & 29,7 & 14,8 & 36,8 & 117 \\
DP & 2,87 & 4,39 & 2,21 & 1,32 & 3,87 & 4,32 & 4,35 & 3,39 & 8,66 & 38,1 \\
\hline
\end{tabular}

$\mathrm{AP}=$ Altura da planta $(\mathrm{cm}) ; \mathrm{LP}=$ Largura da planta $(\mathrm{cm}) ; \mathrm{NCP}=$ Número de cladódios da planta (ud); NC1 =Número de cladódios de primeira ordem (ud); $\mathrm{CC} 1=$ Comprimento do cladódio de primeira ordem $(\mathrm{cm}) ; \mathrm{CC} 2=$ Comprimento do cladódio de segunda ordem $(\mathrm{cm}) ; \mathrm{ECB}=$ Espessura do cladódio basal $(\mathrm{mm}) ; \mathrm{EC} 1$ = Espessura do cladódio de primeira ordem $(\mathrm{mm}) ;$ PC2 = Perímetro do cladódio de segunda ordem $(\mathrm{cm}) ;$ e AC2 = Área do cladódio de segunda ordem $\left(\mathrm{cm}^{2}\right)$.

Outros estudos também citam a ausência de resposta da palma quando submetida a eventos de irrigação. Merwer et al. (1997) verificaram que nas condições climáticas de Pretória, Semiárido da África do Sul, lâminas de irrigação de $12,0 \mathrm{~mm}$ aplicadas a cada sete dias durante sete meses de ciclo, nos meses mais secos, em geral não contribuíram significativamente para o incremento produtivo em termos de massa fresca dos cladódios de clones de palma para fruto. Hernández et al. (2004), analisando o desempenho de clones de palma forrageira submetidos a eventos semanais de irrigação (740 mm ano ${ }^{-1}$ ou 14,2 $\mathrm{mm}$ a cada sete dias; $1060 \mathrm{~mm}^{-1} \mathrm{ano}^{-1}$ ou $20,4 \mathrm{~mm}$ a cada sete dias; e $1380 \mathrm{~mm}^{-1}$ ou $26,5 \mathrm{~mm}$ a cada sete dias), com base na evaporação do Tanque Classe A, no município de Gómez Palacio, Durango, Semiárido do México, observaram que as mesmas não promoveram incremento na produtividade da cultura. Apesar disso, foi possível verificar diferenças significativas entre os clones avaliados $(\mathrm{P}<0,05)$, onde se destacou o clone C-69 pelo maior índice de área do cladódio, e o C-40, que apresentou maior taxa de assimilação líquida, ambos pertencentes ao gênero Opuntia.

Os valores médios das variáveis $\mathrm{AP}$ e LP $(48,8$ e $51,8 \mathrm{~cm})$ para a palma irrigada são próximos aos citados por Sales et al. (2009), em estudo realizado em São João do Cariri, Paraíba, com oito clones de palma forrageira, em condições de sequeiro, onde as alturas das plantas atingiram valores no primeiro ano produtivo entre 30 e $60 \mathrm{~cm}$ a depender do clone, quando a precipitação média anual foi de $619 \mathrm{~mm}$. Todavia, são inferiores aos relatados por Gomes (2011), em experimento conduzido em Assunção, no Cariri Paraibano, onde a precipitação pluviométrica foi de $913 \mathrm{~mm}$ durante 360 dias após o plantio e a AP foi em média igual a 79,8 cm, a depender de diferentes doses de adubação orgânica.

$\mathrm{O}$ número de cladódios por plantas (NCP) exibiu uma média de 12,4 unidades por clone (Tabela 1), o qual é superior ao encontrado por Sales et al. (2009), que constataram de até 5 unidades por clone no primeiro ano. $\mathrm{O}$ número de cladódios de primeira ordem (NC1) em condições irrigadas demonstrou boa magnitude (6,67 unidades). Esse valor é superior ao mencionado por Araújo Primo (2013), de 4,45 unidades, por Silva et al. (2010), que foi de 2,82 unidades, ambos em dois anos de ciclo, e por Oliveira Júnior et al. (2009), que encontraram 3,92 unidades. Por sua vez, as variáveis ECB e AC2 tiveram médias de $29,73 \mathrm{~mm}$ e $116,70 \mathrm{~cm}^{2}$, respectivamente. Esses valores estão abaixo dos encontrados por Araújo Primo (2013), que foram nessa ordem de $34,14 \mathrm{~mm}$ e $263,78 \mathrm{~cm}^{2}$, indicando que a palma forrageira possui maior crescimento dessas varáveis no segundo ano do ciclo produtivo, quando comparado ao primeiro ano. Comportamentos semelhantes entre os três clones foram identificados com base nos valores médios do CC1, CC2, EC1 e PC2 (Tabela 1).

Houve interação significativa entre os fatores clone e disponibilidade de água apenas na espessura do cladódio de segunda ordem (EC2), na condição de F14 para o clone IPA Sertânia, e nas variáveis referentes ao número de cladódios de segunda ordem (NC2) e largura dos cladódios de segunda ordem (LC2) na condição de F14 para o clone OEM (Tabela 2). Para a variável EC2, na condição de F14 no clone IPA Sertânia, foi constatada a média de 5,0 $\mathrm{mm}$, a qual é considerada baixa quando comparada com as demais condições hídricas de cultivo deste clone. Este valor está abaixo do encontrado por Araújo Primo (2013), de 9,56 mm, após dois anos de ciclo em sequeiro, e do relatado por Silva et al. (2010), de $18 \mathrm{~mm}$ para a EC2.

A variável NC2 (Tabela 2), na condição de F14 para o cultivo do clone OEM, foi a que exibiu a menor média (1,56 unidades), a qual está próxima do menor valor encontrado por Silva et al. (2010), de 1,3 unidades, e atingiu 6,8 unidades, assemelhandose à condição de F7 para o clone OEM. Araújo Primo (2013) cita a média de 7,33 unidades para a OEM. Por sua vez, a variável LC2, na condição de F14 para o clone OEM (Tabela 2), diferiu das demais médias, devido não ter ocorrido o surgimento de cladódios de segunda ordem. Neste caso, Araújo Primo (2013) cita médias obtidas em torno de 22,94 $\mathrm{cm}$.

Na comparação dos diferentes clones de palma forrageira na mesma condição de irrigação, verificou-se que algumas variáveis de crescimento, conforme demonstradas na Tabela 3, apresentaram diferenças significativas. 
Tabela 2. Valores médios das variáveis de crescimento de clones de palma forrageira (IPA: IPA Sertânia; MIU: Miúda, OEM: Orelha de Elefante Mexicana) avaliados durante o mês de fevereiro de 2013 em diferentes condições de disponibilidade hídrica no município de Serra Talhada (PE).

\begin{tabular}{|c|c|c|c|}
\hline Clone & Variável & Condição (F) & Médias \\
\hline \multirow{3}{*}{ IPA } & \multirow{3}{*}{$\mathrm{EC} 2$} & 7 dias & $21,0 \mathrm{a}$ \\
\hline & & 14 dias & $5,00 \mathrm{~b}$ \\
\hline & & 28 dias & $15,2 \mathrm{ab}$ \\
\hline \multirow{6}{*}{ OEM } & \multirow{3}{*}{$\mathrm{NC} 2$} & 7 dias & $7,67 \mathrm{a}$ \\
\hline & & 14 dias & $1,56 \mathrm{~b}$ \\
\hline & & 28 dias & $4,22 \mathrm{a}$ \\
\hline & \multirow{3}{*}{ LC2 } & 7 dias & $12,7 \mathrm{a}$ \\
\hline & & 14 dias & $0,00 \mathrm{~b}$ \\
\hline & & 28 dias & $12,5 \mathrm{a}$ \\
\hline
\end{tabular}

*Médias seguidas pela mesma letra na horizontal para a mesma variável de crescimento não diferem estatisticamente entre si pelo teste de Tukey ao nível de $5 \%$ de probabilidade.

EC2 =Espessura do cladódio de segunda ordem ( $\mathrm{mm}$ ), NC2= Número de cladódios de segunda ordem (ud); e LC2=Largura do cladódio de segunda ordem $(\mathrm{cm})$.

Tabela 3. Valores médios das variáveis de crescimento de clones de palma forrageira (IPA: IPA Sertânia; MIU: Miúda, OEM: Orelha de Elefante Mexicana) avaliados durante o mês de fevereiro de 2013 em diferentes condições de disponibilidade hídrica no município de Serra Talhada (PE).

\begin{tabular}{lcccccc}
\hline & CCB & LCB & LCB & LCB & LC1 & LC1 \\
\hline Clone & 28 dias & 7 dias & 14 dias & 28 dias & 7 dias & 14 dias \\
\hline IPA & $18,2 \mathrm{a}$ & $15,9 \mathrm{~b}$ & $18,6 \mathrm{ab}$ & $16,7 \mathrm{ab}$ & $11,0 \mathrm{~b}$ & $13,5 \mathrm{a}$ \\
MIU & $11,0 \mathrm{~b}$ & $12,0 \mathrm{~b}$ & $10,8 \mathrm{~b}$ & $11,1 \mathrm{~b}$ & $9,4 \mathrm{~b}$ & $8,4 \mathrm{~b}$ \\
OEM & $17,2 \mathrm{a}$ & $24,6 \mathrm{a}$ & $25,2 \mathrm{a}$ & $23,1 \mathrm{a}$ & $18,7 \mathrm{a}$ & $15,4 \mathrm{a}$ \\
\hline & LC1 & PCB & PCB & PCB & PC1 & PC1 \\
\hline Clone & 28 dias & 7 dias & 14 dias & 28 dias & 7 dias & 28 dias \\
\hline IPA & $11,2 \mathrm{~b}$ & $42,7 \mathrm{ab}$ & $49,3 \mathrm{a}$ & $48,8 \mathrm{a}$ & $49,1 \mathrm{ab}$ & $55,7 \mathrm{a}$ \\
MIU & $6,83 \mathrm{c}$ & $33,5 \mathrm{~b}$ & $31,8 \mathrm{~b}$ & $28,9 \mathrm{~b}$ & $40,8 \mathrm{~b}$ & $29,8 \mathrm{~b}$ \\
OEM & $16,2 \mathrm{a}$ & $51,2 \mathrm{a}$ & $48,3 \mathrm{a}$ & $46,0 \mathrm{a}$ & $68,6 \mathrm{a}$ & $59,0 \mathrm{a}$ \\
\hline & ACB & ACB & ACB & AC1 & AC1 & AC1 \\
\hline Clone & 7 dias & 14 dias & 28 dias & 7 dias & 14 dias & 28 dias \\
\hline IPA & $185 \mathrm{~b}$ & $248 \mathrm{~b}$ & $223 \mathrm{ab}$ & $160 \mathrm{~b}$ & $242 \mathrm{a}$ & $170 \mathrm{~b}$ \\
MIU & $134 \mathrm{~b}$ & $122 \mathrm{~b}$ & $109 \mathrm{~b}$ & $134 \mathrm{~b}$ & $121 \mathrm{~b}$ & $92,5 \mathrm{~b}$ \\
OEM & $357 \mathrm{a}$ & $420 \mathrm{a}$ & $356 \mathrm{a}$ & $285 \mathrm{a}$ & $310 \mathrm{a}$ & $377 \mathrm{a}$ \\
\hline
\end{tabular}

*Médias seguidas pela mesma letra na vertical para a mesma variável de crescimento não diferem estatisticamente entre si pelo teste de Tukey ao nível de $5 \%$ de probabilidade.

$\mathrm{CCB}=$ Comprimento do cladódio basal $(\mathrm{cm}) ; \mathrm{LCB}=$ Largura do cladódio basal $(\mathrm{cm}) ; \mathrm{LC} 1$ = Largura do cladódio de primeira ordem $(\mathrm{cm}) ; \mathrm{PCB}=$ Perímetro do cladódio basal $(\mathrm{cm}) ; \mathrm{PC} 1=$ Perímetro do cladódio de primeira ordem $(\mathrm{cm}) ; \mathrm{ACB}=$ Área do cladódio basal $\left(\mathrm{cm}^{2}\right)$; e $\mathrm{ACl}=$ Área do cladódio de primeira ordem $\left(\mathrm{cm}^{2}\right)$.

No entanto, a variável comprimento do cladódio basal (CCB), na condição de F28 para o clone IPA Sertânia, não se diferenciou da OEM, tendo, porém, esses clones apresentado diferença em relação a MIU. Esse resultado pode ser explicado do ponto de vista morfológico, tendo em vista que os cladódios dos clones IPA Sertânia e OEM comumente são maiores do que o clone MIU.

Resultado semelhante foi detectado nas variáveis $\mathrm{LCB}, \mathrm{LC} 1, \mathrm{PC} 1, \mathrm{ACB}$ e $\mathrm{AC} 1$ sob as distintas frequências de irrigação (Tabela 3 ), em que o clone OEM apresentou as maiores médias nas diferentes condições hídricas. No entanto, foi constatado comportamento diferente para as variáveis $\mathrm{CCB}$ e $\mathrm{PCB}$, em que o clone IPA Sertânia exibiu as maiores médias, ao contrário do clone MIU, que apresentou as médias menores.

Para as variáveis LCB, LC1, PCB, PC1, ACB e $\mathrm{AC} 1$ o clone IPA Sertânia não deferiu da MIU na condição hídrica de F7. Por se tratar do mesmo gênero, se comportam de maneira semelhante nas mesmas condições de disponibilidade de água no solo. A única exceção foi nas variáveis $\mathrm{PCB}$ e $\mathrm{PC} 1$, pois, nestes casos, o clone IPA Sertânia não diferiu da OEM. Para as demais condições (F14 e F28), a OEM não diferenciou da IPA Sertânia, exceto pela ACB e $\mathrm{AC} 1$, respectivamente. Assim, quando há redução da disponibilidade de água no solo esses dois clones tendem a apresentar comportamentos semelhantes. Por outro lado, percebe-se que o clone MIU sofre mais com a redução na disponibilidade de água no solo (Tabela 3). Santos et al. (1997) relatam que no Brasil, em especial na região Nordeste, as cultivares Gigante e Redonda são produzidas, geralmente, em zonas mais secas, enquanto a Miúda é mais sensível às altas temperaturas do ar e conteúdo de água do solo.

Analisando a evolução das taxas de cresci- 
mento (Figuras 2 a 5), observa-se que todas as taxas apresentaram incrementos significativos nos últimos meses do período de crescimento, em decorrência dos eventos mais expressivos de precipitação pluviométrica $(130 \mathrm{~mm})$, que ocorreram, sobretudo, no mês de janeiro de 2013.

Nas variáveis AP e LP dos clones IPA Sertânia e OEM o aumento foi na ordem de $70 \%$ e $60 \%$ para AP e de $37,01 \%$ e $45,26 \%$ para LP, respectivamente, até o final do ciclo (Figura 2a, 2b). Nessas condições, o clone OEM apresentou maior crescimento na sua largura do que na altura (Figura 2a, 2b). Todavia, não foi verificada a mesma resposta para o clone MIU, pois as taxas da AP dos meses de dezembro de 2012 a fevereiro de 2013 e as taxas da LP do meses de janeiro e fevereiro de 2013 não apresentaram diferenças (Figura 2a, 2b). Nesse clone, essas variáveis também tiveram as maiores taxas de crescimento em fevereiro de 2013 , porém não foram diferentes significativamente dos demais clones.
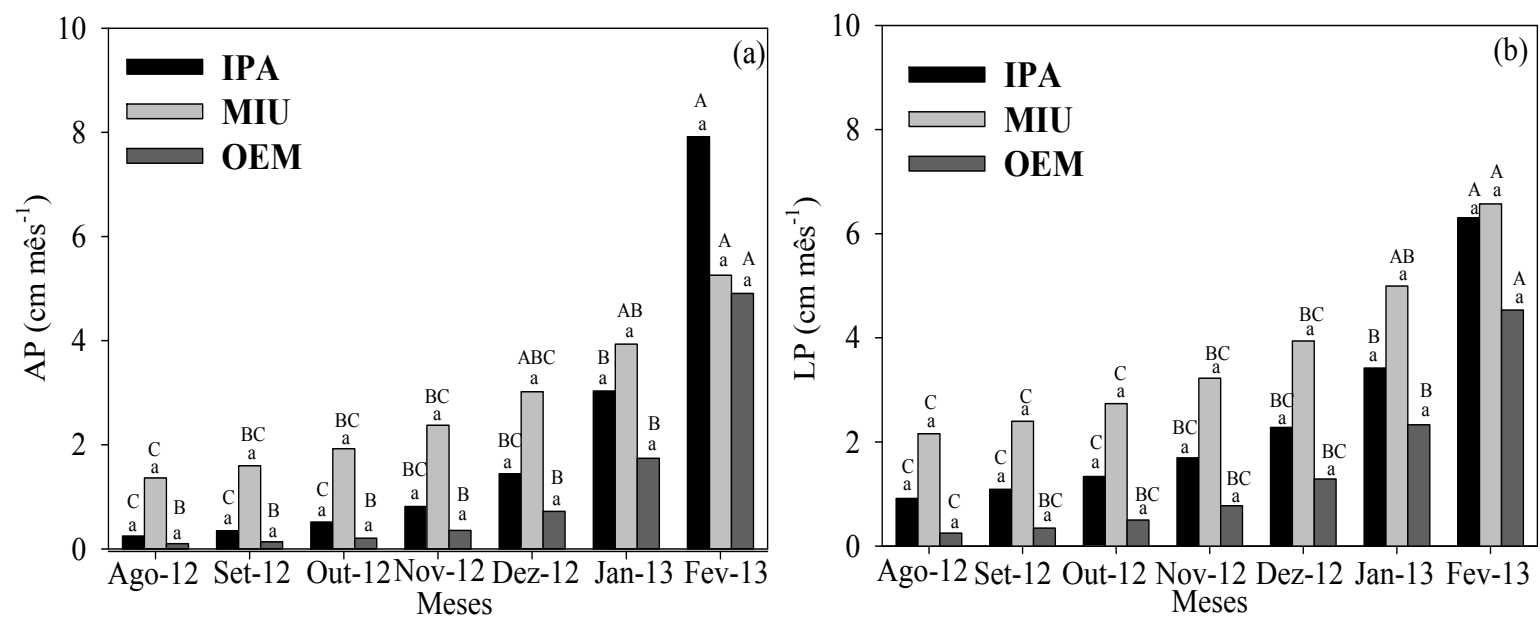

Figura 2. Evolução das taxas de crescimento da altura (a) e largura da planta (b) para clones de palma forrageira (IPA Sertânia, Miúda e Orelha de Elefante Mexicana) cultivados em Serra Talhada, Pernambuco, independentemente da frequência de irrigação.

Taxas seguidas pela mesma letra maiúscula não diferem ao longo do tempo para o mesmo clone e as minúsculas não diferem os clones no tempo, pelo teste de Tukey ao nível de $5 \%$ de probabilidade.

A taxa do NCP (Figura 3a) dos clones IPA Sertânia e OEM no último mês de avaliação do crescimento da palma forrageira se diferenciou dos demais meses do período experimental, proporcionando as maiores taxas de AP e LP (Figura 2a, 2b). Esse fato está associado, principalmente, ao aumento do NC1 (Figura 3b), quando o clone IPA Sertânia alcançou a maior taxa de crescimento, com resultado semelhante à taxa da variável NCP, sendo esse clone o único que se diferenciou ao longo do tempo e mais expressivamente em relação a taxa de $\mathrm{NC} 1$.

Apenas foi possível obter a taxa do $\mathrm{NC} 2$ da MIU (Figura 3c) em decorrência dos demais clones apresentarem valores de cladódios semelhantes ao final do período de avaliação. Dessa forma, esse clone apresentou maior resposta no que se refere à emissão de cladódios de segunda ordem, quando comparado aos clones OEM e a IPA Sertânia. Para a variável CCB (Figura 3d), a OEM apresentou diferença ao longo do tempo, com as maiores taxas em relação aos demais clones. Já para o CC1 (Figura 3e) os clones OEM e IPA Sertânia apresentaram as maiores taxas de crescimento. No que se refere ao $\mathrm{CC} 2$, a MIU apresentou, novamente, os maiores valores de taxas nos últimos meses (Figura 3f). Leite (2009) também constatou baixos valores do comprimento dos cladódios no clone MIU, quando comparado ao clone IPA Sertânia e a outros clones do gênero Opuntia, o que se deve a característica morfológica do referido clone. Assim, a palma MIU compensa, de certa forma, o baixo desenvolvimento de seus cladódios (Figura 3f) pela maior emissão. 

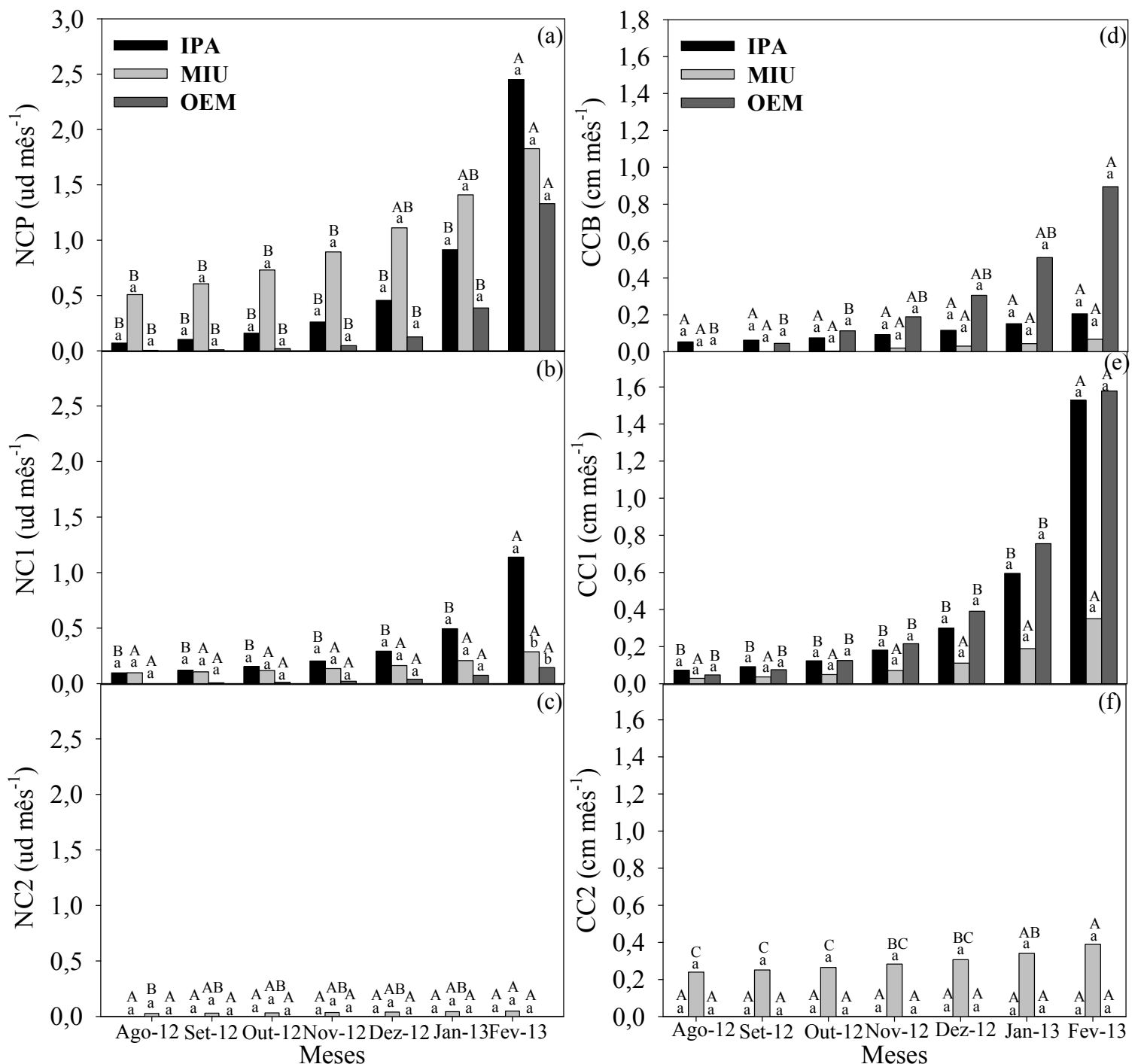

Figura 3. Evolução das taxas de crescimento do número total de cladódio (a), do número de cladódios de $1^{\mathrm{a}}$ e $2^{\mathrm{a}}$ ordem (b, c), comprimento do cladódio basal (d) e comprimento do cladódio de $1^{\mathrm{a}}$ e $2^{\mathrm{a}}$ ordem (e, f) para clones de palma forrageira (IPA Sertânia, Miúda e Orelha de Elefante Mexicana) cultivados em Serra Talhada, Pernambuco.

Taxas seguidas pela mesma letra maiúscula não diferem ao longo do tempo para o mesmo clone e as minúsculas não diferem os clones no tempo, pelo teste de Tukey ao nível de 5\% de probabilidade.

As variáveis LCB e LC1 (Figura 4a, 4b) da OEM diferiram ao longo do tempo (período de avaliações biométricas) em relação aos clones IPA Sertânia e MIU. Com os resultados das taxas de CCB e CC1 e de LCB e LC1 o clone OEM foi o que melhor respondeu ao incremento de água pela chuva nos meses finais, tendo apresentado, durante todos os meses, as maiores taxas de comprimento do que de largura (Figura 4a, 4b). Para a variável LC2 (Figura 4c), o clone MIU apresentou taxa de crescimento acumulado nos dois últimos meses de $57,15 \%$ da taxa total.

Nas avaliações de janeiro e fevereiro de 2013 observaram-se diferenças na LC1 entre os clones e, novamente, a OEM apresentou as maiores taxas. No que se refere à variável ECB (Figura 4d) apenas a OEM apresentou diferença ao longo do tempo, alcançando $28,3 \%$ da taxa de crescimento total no mês fevereiro de 2013. Para a EC1 (Figura 4e), os clones IPA Sertânia e OEM apresentaram o mesmo comportamento, com os maiores valores no último mês de 34,6 e $51,1 \%$ do crescimento total, respectivamente. Finalmente, para a EC2 (Figura 4f), a MIU acumulou 40,6\% da taxa total no mês de fevereiro de 2013, tendo esse mês se diferenciado dos demais.

O clone MIU, para a maioria das variáveis de crescimento, demonstrou os menores valores quando comparado ao IPA Sertânia e OEM. Resultado semelhante foi encontrado por Sales et al. (2009), que trabalharam em São João do Cariri, Paraíba, com oitos clones de palma forrageira, dos quais incluíam a IPA Sertânia e a MIU. Entretanto, os autores obtiveram os menores valores de espessura no clone MIU, sendo os maiores valores observados nos clones do gênero Opuntia. Leite (2009) afirma que para as condições ambientais do Cariri paraibano, região 
do Sertão do Estado, clones do gênero Nopalea apresentam maior dificuldade de estabelecimento no campo quando comparados aos clones do gênero Opuntia.

Ao mesmo tempo em que clone OEM se sobressaiu na largura e no comprimento dos cladódios, nas condições expostas neste experimento, ele também exibiu as maiores taxas para a variável espessura, demonstrando que possui capacidade de acumular mais água que os demais. O resultado de espessura encontrado neste trabalho também sugere que os clones OEM e IPA Sertânia devem ter maior potencial de adaptação às condições de baixa disponibilidade de água no solo do que o clone MIU, por apresentarem maior capacidade de reserva hídrica, fato este também constatado por Leite (2009). Nesse contexto, a turgidez é um dos principais atributos das plantas CAM, a qual é expressa morfologicamente ou anatomicamente por meio dos cladódios espessos, com a presença de vacúolos cheios de água nas células fotossintéticas, e também pelas diversas camadas de células armazenadoras de água. Os cladódios maduros têm, geralmente, espessura maior, sendo que a maior parte é constituída pelo tecido esbranquiçado armazenador de água (NOBEL, 2001).

Com relação às taxas de $\mathrm{PCB}$ e $\mathrm{PC} 1$ (Figura $5 \mathrm{a}, 5 \mathrm{~b})$, os clones IPA Sertânia e MIU não se diferenciaram ao longo do tempo $(\mathrm{P}>0,05)$. Entretanto, o clone OEM, semelhantes às demais variáveis, exibiu uma elevação nas suas taxas no último mês, sendo que para o $\mathrm{PCB}$, neste período, houve diferença apenas nos três primeiros meses, e para o $\mathrm{PC} 1$ só não diferenciou do mês de janeiro de 2013. Similarmente, a OEM se diferenciou dos demais clones para as taxas de PC1 no último mês de avaliação (Figura $5 b)$.

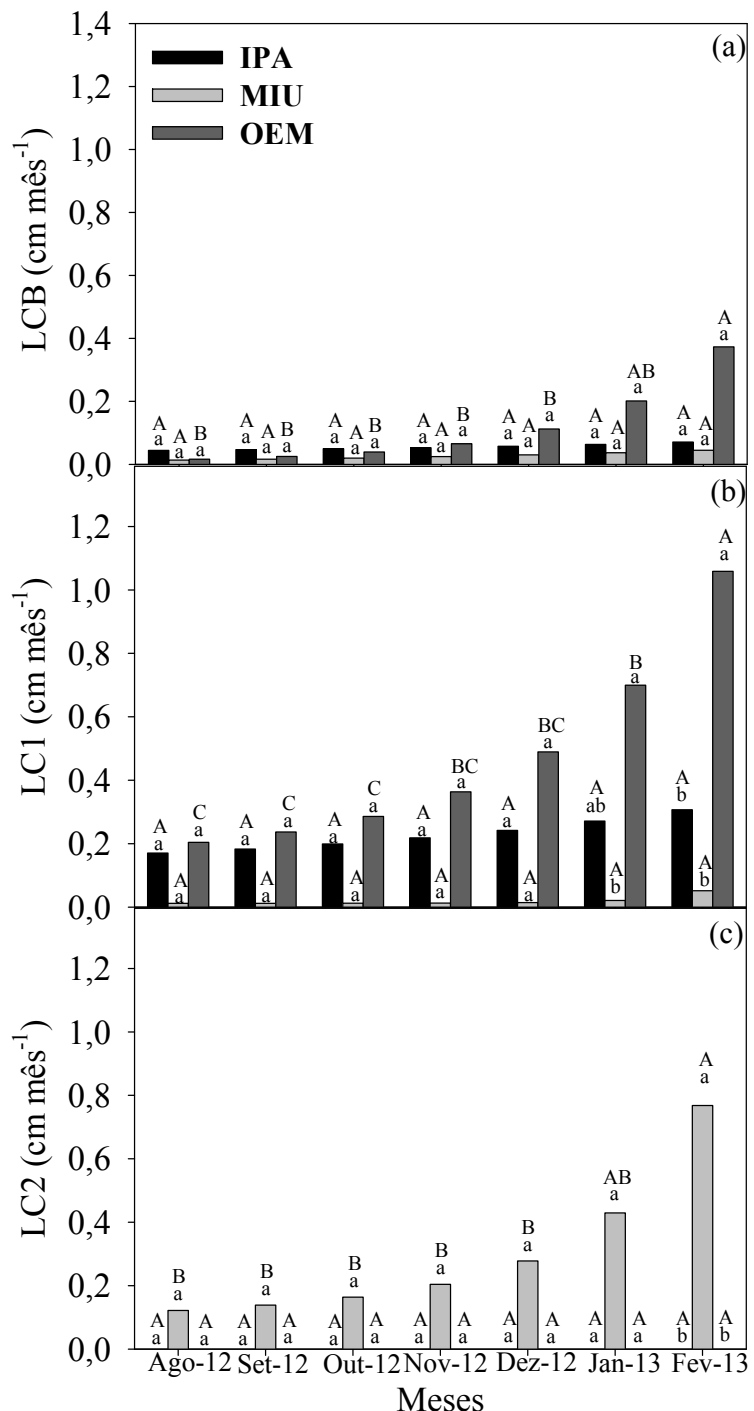

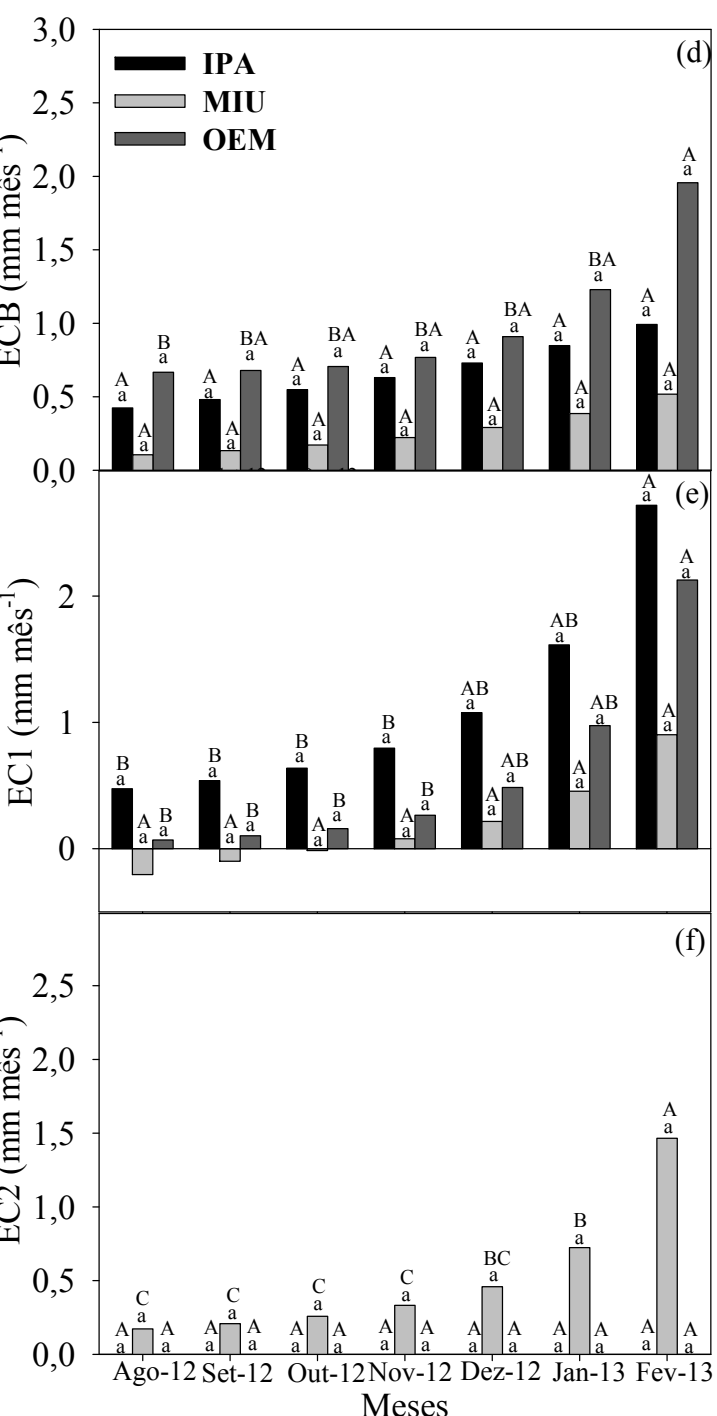

Figura 4. Evolução das taxas de crescimento da largura do cladódio basal (a), da largura do cladódio basal de $1^{\mathrm{a}}$ e $2^{\mathrm{a}}$ ordem $(b, c)$, da espessura do cladódio basal (d) e da espessura do cladódio de $1^{a}$ e $2^{a}$ ordem (e, f) para clones de palma forrageira (IPA Sertânia, Miúda e Orelha de Elefante Mexicana) cultivados em Serra Talhada, Pernambuco.

Taxas seguidas pela mesma letra maiúscula não diferem ao longo do tempo para o mesmo clone e as minúsculas não diferem os clones no tempo, pelo teste de Tukey ao nível de 5\% de probabilidade. 

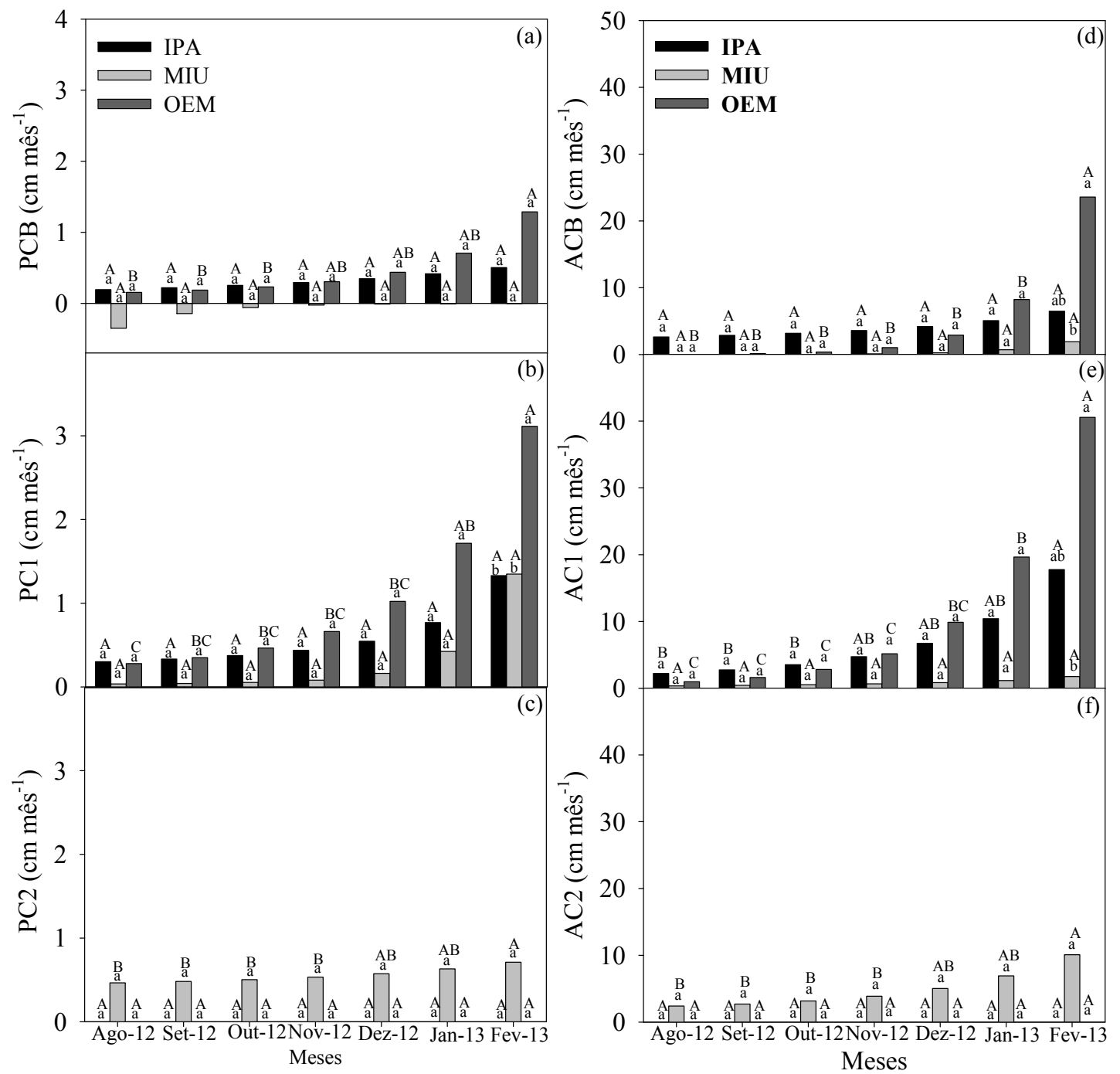

Figura 5. Evolução das taxas de crescimento de largura do perímetro basal (a), do perímetro do cladódio basal de $1^{\mathrm{a}}$ e $2^{\mathrm{a}}$ ordem (b, c), da área do cladódio basal (d) e da área do cladódio de $1^{\mathrm{a}}$ e $2^{\mathrm{a}}$ ordem (e, f) para clones de palma forrageira (IPA Sertânia, Miúda e Orelha de Elefante Mexicana) cultivados em Serra Talhada, Pernambuco.

Taxas seguidas pela mesma letra maiúscula não diferem ao longo do tempo para o mesmo clone e as minúsculas não diferem os clones no tempo, pelo teste de Tukey ao nível de 5\% de probabilidade

As taxas de PC2 (Figura 5c) do clone MIU, no último mês de avaliação, apresentaram diferenças em relação aos quatro meses iniciais, tendo os outros três meses contribuído com aproximadamente $49,2 \%$ da taxa total. Em relação às taxas de crescimento da ACB o único clone que se diferenciou ao longo do tempo foi a OEM, o qual apresentou novamente a maior taxa (Figura 5d). Para as taxas de AC1, os clones IPA Sertânia e OEM apresentaram, respectivamente, no último mês crescimento equivalentes a $39,8 \%$ e $50,3 \%$ da taxa acumulada total (Figura $5 \mathrm{e}$ ). Observou-se diferenças entre os clones no mês de fevereiro de 2013, tanto em relação à $\mathrm{ACB}$ quanto a AC1, tendo a OEM e a IPA Sertânia apresentado maiores taxas de crescimento do que a MIU.

A taxa de AC2 do clone MIU nos três últimos meses apresentou crescimento de $29,5 \%$ do total
(Figura 5f). Oliveira Junior et al. (2009) relatam que a variação da área de cladódio ao longo do tempo depende das condições edafoclimáticas, manejo adotado, cultivar utilizada, densidade populacional, idade da cultura e outros fatores, sendo que, geralmente, a taxa da área de cladódio aumenta até um máximo e decresce após algum tempo.

\section{CONCLUSÃO}

Durante o primeiro ano produtivo do segundo ciclo da palma forrageira, com a ocorrência de anomalia climática, as diferentes condições de disponibilidade hídrica $(7,5 \mathrm{~mm}$ a cada 7,14 e 28 dias) influenciaram poucas variáveis de crescimento dos clones. 
Os clones Orelha de Elefante Mexicana e a IPA Sertânia demonstraram evolução das variáveis biométricas superiores à Miúda, nas condições irrigadas do Semiárido brasileiro.

\section{REFERÊNCIAS}

ANDRADE, A. P. et al. Produção animal no semiárido: o desafio de disponibilizar forragem, em quantidade e com qualidade, na estação seca. Tecnologia \& Ciência Agropecuária, João Pessoa, v. 4, n. 4, p. 01-14, 2010.

ARAÚJO PRIMO, J. T. Dinâmica de água no solo e eficiência do uso de água em clones de palma forrageira no semiárido pernambucano. 2013. 108 f. Dissertação (Mestrado em Produção Vegetal) - Universidade Federal Rural de Pernambuco, Unidade Acadêmica de Serra Talhada, Serra Talhada, 2013.

BERLATO, M. A.; FARENZENA, H.; FONTANA, D. C. Associação entre El Niño oscilação sul e a produtividade do milho no estado do rio grande do sul. Pesquisa agropecuária brasileira, Brasília, v. 40, n. 5, p. 423-432, 2005.

BISPO, S. V. et al. Palma forrageira em substituição ao feno de capim-elefante. Efeito sobre consumo, digestibilidade e características de fermentação ruminal em ovinos. Revista Brasileira de Zootecnia, Viçosa, v. 36, n. 6, p. 1902-1909, 2007.

CRUZ, C.D. GENES - a software package for analysis in experimental statistics and quantitative genetics. Acta Scientiarum, Maringá, v. 35, n. 3, p. 271276,2013

CUNHA, D. N. F. V. et al. Morfometria e acúmulo de biomassa em palma forrageira sob doses de nitrogênio. Revista Brasileira Saúde Produção Animal, Salvador, v. 13, n. 4, p. 1156-1165, 2012.

GOMES, J. B. Adubação orgânica na produção de palma forrageira (Opuntia ficus-indica (L) Mill.) no cariri paraibano. 2011. 63 f. Dissertação (Mestrado em Zootecnia) - Universidade Federal de Campina Grande, Patos, 2011.

HERNÁNDEZ, A. F. et al. Enrique Troyo-Dieguezc Yield and physiological traits of prickly pear cactus 'nopal' (Opuntia spp.) cultivars under drip irrigation. Agricultural Water Management, Amsterdam, v. 70, n. 2, p. 97-107, 2004.

LEITE, M. L. M. V. Avaliação de clones de palma forrageira submetidos a adubações e sistematiza- ção de informações em propriedades do Semiárido paraibano. 2009. 186 f. Tese (Doutorado em Zootecnia) - Universidade Federal da Paraíba, Areia, 2009.

MAPLESOFT. The essential tool mathematics and modeling. Disponível em: $<$ http:www.maplesoft.com/products/maple/>. Acesso em: 27 de fevereiro de 2014.

MERWER, L. L. V. D.; WESSELS, A. B.; FERREIRA, D. I., Supplementary irrigation for cactus pear. In: CONGRESS ON CACTUS PEAR AND COCHINEAL. 3., 438, 1997. Midrand, Resumos... Midrand: ISHS Acta Horticulturae, 1997. p. 77-81.

MINUZZI, R. B. et al. Influência do el niño nas épocas de plantio e fenologia da cultura da soja na região. Revista Ceres, Viçosa, v. 54, n. 313, p. 316323, 2007.

MIRANDA, K. R. et al. Modelos de estimativa da área do cladódio de variedades de palma no Semiárido pernambucano. In: CONGRESSO BRASILEIRO PALMA E OUTRAS CACTÁCEAS, 2., 2011, Garanhuns. Anais... Garanhuns: Sociedade Brasileira de Palma e outras Cactáceas, 2011.

NOBEL, P. S. Biologia ambiental. In: BARBERA, G.; INGLESE, P. Agroecologia, cultivo e usos da palma forrageira. SEBRAE/PB, João Pessoa: SEBRAE/PB, 2001. p. 36-48.

OLIVEIRA JUNIOR, S. et al. Crescimento vegetativo da palma forrageira (Opuntia fícus-indica) em função do espaçamento no Semiárido paraibano. Tecnologia \& Ciência Agropecuária, João Pessoa, v. 3, n. 1, p. 7-12, 2009

OLIVEIRA, E. C. et al. Effects of water deficit in two phenological stages on production of japanese cucumber cultived in greenhouse. Engenharia Agrícola, Jaboticabal, v. 31, n. 4, p. 676-68, 2011.

RAMOS, J. P. F. et al. Crescimento vegetativo de Opuntia ficus-indica em diferentes espaçamentos de plantio, Revista Caatinga, Mossoró, v. 24, n. 3, p. 41-48, 2011.

SALES, A. T. et al. Adaptation potential of cactos pear to soil and climatic conditions of the Semi-arid in Paraíba State, Brazil. In: CONGRESS ON CACTUS PEAR AND COCHINEAL, 6., 2009, João Pessoa, Resumos... João Pessoa: ISHS Acta Horticul- 
turae, 2009. p. 395-400.

SANTOS, D. S. et al. Cultivares de trigo submetidas a déficit hídrico no início do florescimento, em casa de vegetação, Revista Brasileira de Engenharia Agrícola e Ambiental, Campina Grande, v. 16, n. 8, p. 836-842, 2012.

SANTOS, D. C. et al. A palma forrageira (Opuntia ficus-indica Mill e Nopalea cochenillifera SalmDyck) em Pernambuco: cultivo e utilização. Recife: IPA (Documentos IPA, 25), 23 p. 1997.

SIGMAPLOT. 2004. For windows, version 9.01. Systat Software, 2004.

SILVA, T. G. F. et al. Área do cladódio de clones de palma forrageira: modelagem, análise e aplicabilidade. Agrária, Recife, v. 9, n. 4, p. 633-641, 2014.

SILVA, J. A. L.; NEVES, J. A. Produção de feijãocaupi semi-prostrado em cultivos de sequeiro e irrigado. Revista Brasileira de Ciências Agrárias, Recife, v. 6, n. 1, p. 29-36, 2011.

SILVA, N. G. M. et al. Relação entre características morfológicas e produtivas de clones de palmaforrageira. Revista Brasileira de Zootecnia, Viçosa, v. 39, n. 11, p. 2389-2397, 2010.

SOUZA, L. S. B. et al. Indicadores climáticos para o zoneamento agrícola da palma forrageira (Opuntia sp.). In: III JORNADA DE INICIAÇÃ̃O CIENTIFICA DA EMBRAPA SEMI-ÁRIDO, 2008, Petrolina. Anais... Petrolina: Embrapa Semi-Árido, 2008.

TEGEGNE, F.; KIJORA, C.; PETERS, K. J. Study on the optimal level of cactus pear (Opuntia ficusindica) supplementation to sheep and its contribution as source of water. Small Ruminant Research, Amsterdam, v. 72, n. 2-3, p. 157-164, 2007. 